\title{
Visita a una baldada: el encuentro paiteño de Manuela Sáenz y Ricardo Palma
}

\author{
Juan Carlos Adriazola Silva \\ Instituto de Estudios Histórico Marítimos del Perú \\ adriazola46@yahoo.es \\ Lima-Perú
}

\section{Resumen}

La forma como llegan a vincularse dos personajes de relieve en la historia del Perú y el Ecuador, como son Manuela Sáenz Aizpuru y Ricardo Palma Soriano, es un asunto de trascendencia que no puede pasar inadvertido en el estudio exhaustivo de la obra palmina. Todo comenzó, al parecer, con una simple y curiosa visita de cortesía que éste le hiciera a aquella baldada en su paupérrima casa del puerto piurano de Paita, allá por el año de 1856. Dicho encuentro serviría especialmente a Palma de pretexto para la creación de algunas sabrosas tradiciones en las que dio a conocer diversos aspectos del genio y figura de quien fue considerada una destacada patriota en el Perú durante el periodo sanmartiniano de la Independencia; y, más tarde, una celebridad, muchas veces aborrecida, por ser la favorita del Libertador Simón Bolívar. La vida de esta mujer es intensa, y está signada desde la infancia por la dureza de los desafectos, que la convirtieron en una joven rebelde y decidida que no temería en el futuro a nada ni a nadie. Al entrar en la madurez, llegó, sin embargo, a conocer el lujo, el glamur y la gloria que vienen con el poder. Muerto su héroe amado, la venganza de los enemigos de Bolívar la alcanzó, lo que se tradujo en un prolongado destierro político, agravado por el abandono, la enfermedad y la pobreza. Su trayectoria vital la hace digna de engalanar la galería de mujeres significativas de la historia hispanoamericana que rebasan la primera mitad del siglo XIX.

Palabras clave: Manuela Sáenz, José de San Martín, Simón Bolívar, James Thorne, Independencia del Perú, El Libertador, La Libertadora.

\section{Abstract}

The way in which two prominent figures in the history of Peru and Ecuador, Manuela Sáenz Aizpuru and Ricardo Palma Soriano, became related is a 
transcendental matter that cannot go unnoticed in the exhaustive study of the work of Palma. It seems that it all began with a simple and curious courtesy visit that he made to that wasteland in her poor house in the Piuran port of Paita in 1856. This meeting would serve especially to Palma as a pretext for the creation of some flavorous traditions in which he made known various aspects of the genius and figure of the one who was considered an outstanding patriotic woman in Peru during the period of Independence of San Martin; and later, a celebrity often loathed for being the favorite of the Liberator Simón Bolivar. The life of this woman is intense and is marked since childhood by the harshness of the disaffects, which turned her into a rebellious and determined young woman who would not fear anything or anyone in the future. As she entered maturity, however, she came to know the luxury, glamour and glory that come with power. When his beloved hero died, the revenge of Bolivar's enemies caught up with her. This resulted in a prolonged political exile, aggravated by abandonment, illness and poverty. Its vital trajectory makes it worthy of adorning the gallery of significant women of Hispanic American history that go beyond the first half of the nineteenth century.

Keywords: Manuela Sáenz, José de San Martín, Simón Bolivar, James Thorne, Independence of Peru, The Liberator ("El Libertador", "La Libertadora").

Juan Carlos Adriazola Silva (Piura): Doctor en Educación por la Universidad Nacional de Piura. Magíster en Investigación y Docencia por la Universidad Nacional Pedro Ruiz Gallo de Lambayeque. Periodista por la Universidad de Piura. Diplomado en Relaciones Internacionales por la Academia Diplomática del Perú. Miembro Correspondiente del Instituto Ricardo Palma, Miembro del Instituto de Estudios Histórico Marítimos del Perú, Centro de Estudios Histórico Militares e Instituto Libertador Ramón Castilla, entre otros. 


\section{Tras las huellas de Manuela Sáenz en archivos de dos países}

En octubre de 1999, hace exactamente 20 años, gracias al apoyo de la Casa de la Cultura Ecuatoriana tuve la oportunidad de viajar por primera vez a la capital del Ecuador para realizar una investigación sobre la vida de doña Manuela ${ }^{1}$ Sáenz Aizpuru (nacida en Quito en 1795), con el propósito de recoger, hasta donde fuera posible, la mayor cantidad de información que me llevara a entender de forma cabal a este personaje histórico y de leyenda, que atrajo poderosamente mi atención e interés desde que supe de ella y visité su destartalada casa en la ciudad-puerto de Paita en el verano de 1995. Las pesquisas, documentales y bibliográficas, que realicé en el Archivo Histórico Nacional, en el Archivo Juan José Flores de la Pontificia Universidad Católica del Ecuador, en el Archivo Metropolitano de Historia, en el Fondo Jacinto Jijón y Caamaño del Archivo Histórico del Banco Central del Ecuador, así como las visitas al Archivo de la ex casa-hacienda Cataguango y al museo quiteño que Carlos Álvarez Saá creó ex profesamente para perpetuar la memoria de la fiel compañera de Simón Bolívar, me dieron el marco referencial que necesitaba para la comprensión integral de la vida de doña Manuela Sáenz y, más específicamente, sobre las causas reales de la pobreza que esta dama padeció en la ciudad-puerto de Paita durante las casi dos décadas que estuvo anclada en dicha provincia piurana, primero, como deportada política del gobierno de su país, y luego, como exiliada por propia voluntad. La tarea llevada a cabo en los repositorios quiteños no hubiese sido posible sin la ayuda invalorable del Dr. Jorge Núñez Sánchez de la Academia Nacional de Historia,

I A lo largo de este escrito se llamará siempre al personaje como Manuela, nunca como Manuelita, como muchos biógrafos y escritores se han dado la licencia de nombrarla. Así le gustaba a ella presentarse a sí misma, según la infinidad de cartas escritas a El Libertador, a familiares y a amigos. Es lo que corresponde a una mujer de gran temple y valor, que nunca claudicó a su manera de ser e ideales 
de la Dra. Maritza Aráuz Castro del Ministerio de Relaciones Exteriores y del Dr. Jorge Salvador Lara, entonces ex Canciller de la República y Cronista de la Ciudad de Quito, quienes me abrieron importantes puertas y con su cálida hospitalidad y fraterna amistad, me hicieron sentir verdaderamente como en casa durante las semanas que duró mi estadía en la bella ciudad andina ubicada en las faldas del Pichincha.

Esta comunicación que hoy se presenta al Instituto Ricardo Palma es un adelanto de lo que será, en su momento, una publicación de mayor envergadura.

\section{¿Por qué visita a una "baldada"?}

Desde que las palabras de la lengua castellana (hoy llamada española) se recogieron por primera vez en un lexicón en la primera mitad del siglo XVIII, como es el Diccionario de Autoridades de la Real Academia, se ha utilizado el término "baldada" (del part. de baldar) para referirse a una persona privada o impedida por alguna enfermedad o accidente del uso de todos sus miembros, o de alguno de ellos. Estas personas eran lo que en el antiguo latín se les conocía como membra rigere o membra contrahi, es decir, con los miembros rígidos, contrahechos o tullidos (RAE, 1964, p. 536). Y con este significado ha perdurado "baldada" hasta nuestros días, según puede leerse en la vigesimotercera edición del Diccionario de la Lengua Española (RAE, 2014, vol. 2, p. 268), aunque en la actualidad bien podría considerarse a esta palabra como arcaica, pues casi nadie la conoce o la utiliza en el habla o la escritura general. Si la conoció y la utilizó, en cambio, don Ricardo Palma como queda evidenciado, por ejemplo, en el texto de la misma tradición en la que trata de explicar por qué la favorita de Simón Bolívar había venido a vivir a Paita:

¿Qué motivos tuvo la amada de Bolívar para venir a establecerse y a morir en uno de los, por entonces, más 
tristes lugarejos del Perú? La pobre baldada me dijo, un día en que aventuré la pregunta, que había elegido Paita por consejo de un médico, quien juzgaba que con baños de arena recobrarían los nervios de la enferma la flexibilidad perdida (1957: 1134).

La mencionada flexibilidad perdida, más que producto del padecimiento de una enfermedad crónica (aunque algunos afirman sufría de reumatismo ${ }^{2}$ ) o de un mal adquirido por contagio, debióse a un accidente inesperado dentro de su hogar, según puede leerse en el informe de extrema pobreza que presentó en el juicio seguido en Lima su apoderado Cayetano Freyre, quien al momento de rebatir los argumentos de Manuel Escobar, albacea testamentario de James Thorne, dice en su argumentación:

Si doña Manuela tuviese alguna propiedad suya, no se encontraría hoy en Paita, viviendo en una buhardilla miserable, tirada en una hamaca sin poder moverse por tener dislocado un hueso del cuadril; no tendría necesidad de ser alimentada y vestida a expensas de la piedad de sus amigos, porque esta humillación no la soporta la persona que tiene de que subsistir, ni menos la toleraría mi representada en su extremada delicadeza; ni tampoco habrían personas que le prestasen sus auxilios en semejante caso que sólo tiene existencia en la imaginación de don Manuel (AGN, 1975, p. 259).

En efecto, cuando doña Manuela estaba por cumplir sus 50 años de edad, al bajar la escalera del segundo piso de la casa que

2 Esta afirmación no está del todo comprobada como bien desarrolla en su nota 11, Pamela Murray, 2010, p.224; Asimismo, por el reumatismo se dice que Manuela tuvo cerca muchos perros, especialmente, los llamados perros sin pelo del Perú, pues es sabido que el calor o alta temperatura que emite el cuerpo de estos caninos, son especie de bolsas de agua caliente que alivian el mal de quien sufre dicha enfermedad. Es interesante señalar que a Manuela le gustaba regalar estos perros a sus amigos. Cartas de Manuela a Ascasubi del 13/III/5 I y 30/III/5 1, en Borja, L.F...1946, pp. 241-242. 
ocupaba, una mala pisada hizo que rodara abajo fracturándose el hueso de la cadera. El accidente logró lo que adversidades anteriores no habían podido con ella: frenar su ímpetu, dejarla quieta y dependiente para siempre de los demás. Por eso cuando Ricardo Palma y Manuela Sáenz se encontraron en Paita, en 1856, la favorita del Libertador era corporalmente una persona membra rigere o membra contrahi, no obstante, seguía poseyendo sus facultades mentales intactas que la hicieron una interlocutora valida de recuerdos, experiencias y afectos que el joven Palma captó entonces, y que recordaría años después al hacer referencia directa de la ilustre quiteña en cuatro de sus tradiciones enmarcadas a inicios del periodo republicano.

\section{¿Cómo llegó Manuela a residir en Paita?}

En octubre de 1835 quiso Manuela Sáenz retornar al Ecuador, después de siete años completos de ausencia de su patria natal. Gobernaba el país desde el 8 de agosto pasado, el señor Vicente Rocafuerte y Rodríguez de Bejarano quien desde hacía mucho tiempo se había declarado enemigo de Bolívar y de todos los cercanos a él. El general Juan José Flores recién había acabado su primer periodo de gobierno y casi de inmediato fue designado Jefe Militar del Guayas. Manuela Sáenz se entrevistó con Flores tan pronto como arribó al puerto de Guayaquil, ya que era su viejo amigo desde el año 22, año de la llegada de Bolívar a Quito. Por ese motivo, Flores dirige una carta al Presidente de la República recomendando a su protegida y dándole las seguridades sobre su pacífico comportamiento ${ }^{3}$. Con esta misiva, la Sáenz se puso en marcha hacia la capital del Pichincha. Rocafuerte, sin embargo, al enterarse de la llegada de la Sáenz a suelo ecuatoriano, montó en cólera por el odio

3 Carta de Vicente Rocafuerte a Juan José Flores, fechada en Quito el 21/X/1835 (Landázuri, 1988, t. I, p.213). 
que le tenía ${ }^{4}$ y ordenó de inmediato a su ministro José Miguel Gonzáles Alminati, que redactara un documento acusándola de regresar al Ecuador para vengar la muerte de su hermano, el general José María Sáenz Del Campo ${ }^{5}$, caído en la Batalla del Pesillo, el $2 \mathrm{I}$ de abril de 1834, combatiendo contra el gobierno de Flores. Nada se pudo hacer contra la orden del presidente e incluso el mismo general Flores quedo resentido por el desaire que el Jefe de Estado hizo a su particular misiva. Doña Manuela no contaba con recursos para emprender este nuevo destierro, entonces el general Flores le hizo un préstamo urgente de 300 pesos que le entregó en el buque al momento de partir ${ }^{6}$. Fue así como Manuela Sáenz se vio obligada a trasladarse al Perú, en noviembre del año 35. En este nuevo peregrinar le acompañaron únicamente sus dos jóvenes esclavas Juana Rosa y Dominga.

Dos años después, en aras de la paz y la tranquilidad de la República del Ecuador, la orden del destierro de Manuela fue revocada por el Senado y la Cámara de Representantes el 18/I/1837, y el Poder Ejecutivo, con Rocafuerte a la cabeza, emitió un salvoconducto de retorno a su país, que el Ministro del Interior, Bernardo Daste, se encargó de comunicar (Peña, 1944, pp.308-309); sin embargo, Manuela, reacia por orgullo a esta decisión gubernativa, no lo aceptó. Por otra parte, había empezado a encontrar sosiego y afectos en Paita, y no quiso volver más al Ecuador. Al respecto se lee:

Un terrible anatema del infierno comunicado por Rocafuerte me tiene a mi lejos de mi patria y de mis amigos como usted

4 Carta de Vicente Rocafuerte a Juan José Flores, datada en Quito el 14/X/1835 (Landázuri, 1988, t. I, p. 211 ).

5 Fue hijo de Simón Sáenz de Vergara y Yedra y de Juana María del Campo Larrahondo y Valencia. De todos los diez hijos que tuvo la pareja, José María fue el que más apego y cariño sintió por Manuela a lo largo de los años (Jurado, 1986, pp.200-202).

6 Una década después Manuela devolvió esta cantidad a Juan José Flores. Víd. Carta de Manuela Sáenz a Roberto Ascasubi Matheu, Paita, 5/XI/1845. (Borja, 1946, pp. 236). 
y lo peor es que mi fallo está echado a no regresar al suelo patrio; pues usted sabe, amigo mío, que es más fácil destruir una cosa que hacerla de nuevo; una orden me expatrió; pero el salvoconducto no ha podido hacerme reunir a mis más caras afecciones: mi patria y mis amigos ${ }^{7}$.

\section{De mujer encumbrada a pobre de solemnidad}

En la trayectoria vital de Manuela Sáenz sorprende mucho el hecho de que ella, después de haber gozado de una vida encumbrada en donde la abundancia y el poder eran parte de su cotidianidad, cayera con los años en la más absoluta pobreza, situación ésta que la acompañó hasta el fin de su existencia. Según Pamela Murray, esto fue el efecto de una forma de vida que no había tenido una base sólida y no tendría sostenimiento en el tiempo después de la muerte del Libertador:

Había comenzado a preocuparse por cuestiones prácticas, en particular, por su creciente escasez de dinero. Era un nuevo problema para ella. Siempre había sido mantenida, primero por su padre y su esposo, luego por Bolívar. Estaba acostumbrada a llevar un estilo de vida relativamente lujoso que, como era habitual para la mayoría de sus contemporáneos de clase alta, dependía en gran medida de la presencia de sirvientes (2010, p. 149)

Sin embargo, las estrecheces económicas por las que pasa la Libertadora, tienen una explicación más amplia a partir de la lectura de las innúmeras cartas que dirige a sus apoderados y amigos de confianza en Quito y Lima durante los casi 21 años que está desterrada en Paita. A través de dicha correspondencia, se advierte la persistente lucha que se planteó para obtener la

7 Carta de Manuela Sáenz a Juan José Flores, fechada en Paita el 7/IX/1843, en Villalba,...1986, p.144. 
herencia que le correspondía tanto por el lado materno como por el lado de su progenitor.

De acuerdo con Fernando Jurado Noboa, la herencia materna provenía más que de la madre de Manuela, doña Joaquina Aizpuru y Sierra, de sus abuelos, el abogado y relator de la Real Audiencia de Quito, don Mateo José Aizpuru Montero de Espinoza y de doña Gregoria Sierra Pambley y Mora, casados el 16 de enero de 1749. La pareja llegó a procrear en total diez hijos (1986, p. 209).

Para cuando ocurrió el óbito del doctor Aizpuru, el 14 de setiembre de 1803, ya habían fallecido ocho de sus hijos, entre ellos la madre de Manuela, doña Joaquina, por lo que fueron herederos universales de la considerable fortuna los dos hijos que le sobrevivieron: el presbítero y cura de Yaruqui, Domingo Aizpuru y Sierra e Ignacia Aizpuru viuda de Carlos Antonio del Mazo y Gómez de Villasufre, ambos tíos sanguíneos de Manuela. Al fallecer Domingo Aizpuru en 1819, su herencia pasó automáticamente a poder de su hermana Ignacia, administradora del patrimonio familiar.

En 1821 , Manuela, estando aún en Lima junto a Thorne, tomó la decisión de iniciar los trámites jurídicos para recuperar la herencia de su madre. Para ello, previo poder dado por cónyuge, como correspondía entonces a una mujer que era propiedad y estaba bajo control de su marido, nombró apoderado en Quito a su antiguo confesor en el Monasterio de la Concepción, el sacerdote Juan Manuel Flores, quien se hizo sustituir por Francisco Javier Escudero. Lo primero que debió lograr Escudero, era demostrar ante los tribunales la filiación de Manuela Sáenz respecto a su madre Joaquina Aizpuru, ya que se le consideraba hasta entonces como "expósita", calificación que se aplicaba a todas aquellas personas que nunca conocieron a sus verdaderos padres de sangre. Como en la realidad esto 
no era cierto, Escudero solicitó judicialmente, el 16 de junio de 1821, a fray Mariano Ontaneda, como protector inicial que fue de la recién nacida, para que declarase bajo juramento ${ }^{8}$, lo que expresó en estos términos: “(...) doña Joaquina parió y dio a luz a la mencionada niña, para que la criasen en cierta casa; aunque luego resolviera exponerla en el Monasterio de la Concepción..." (5/IX/1821). Finalmente, Manuela logró que se reconociera su filiación, pero en la práctica su tía Ignacia buscó mil pretextos dilatorios para no entregarle lo que en buena ley le correspondía a su sobrina.

Al retornar Manuela a Quito en 1823, pudo recién ser conminada doña Ignacia Aizpuru y Sierra para ir ante el escribano mayor y de gobierno Juan Antonio Rivadeneira y dejar protocolizado un documento, en donde, entre otros asuntos, se acordó:

Según el testamento del doctor Mateo le correspondía a la señora Manuela mayor cantidad que la de diez mil pesos, poniendo en claro los bienes existentes y los derechos que expresa aquel testamento; que, sin embargo de todo, ha convenido la señora Manuela Sáenz, por obviar pleitos y diferencias de familia, y acelerar su viaje, en percibir diez mil pesos en efectivo, con estas condiciones:

Primera: que se han de satisfacer en moneda física, usual y corriente; dentro de dos años, contados desde esta fecha.

Segunda: que, si no se le pagan en dicho plazo, se le ha de satisfacer el cinco por ciento anual por todo el tiempo de la demora.

8 No se presentó quizá la Partida de Bautismo de Manuela como testimonio de filiación por dos razones obvias: o porque no se encontró, o porque los nombres de los "padres" declarantes no iban a coincidir con los de la realidad; por tanto, en vez de ser una ayuda en el trámite judicial, se constituiría en una prueba en contra del propósito buscado. 
Tercero: que a esta obligación quedan sujetos todos los bienes de doña Ignacia... especial y señaladamente la hacienda de Cotocollao (San Isidro) heredada de su hermano el doctor Pedro José; y para el caso de no alcanzar su contado a cubrir este crédito, la hacienda de Chillo, en el pueblo de Amaguaña, que le vino por título de sucesión.

Entendiéndose que como esta obligación nada tiene de gracia, sino de estricta justicia, consiente la señora Ignacia que la transacción celebrada se entienda no solo por los bienes de los señores abuelos, sino también por los que podía haber poseído de la señora Joaquina su madre, porque su derecho comenzó a existir desde que fallecieron sus citados abuelos, ha de preferir éste a cualesquiera obligaciones que posteriormente haya contraído la señora Ignacia Aizpuru (...)" (AHN, Quito, Protocolos de escribano J.A. Ribadeneyra, 31/VII/1823).

Cuando se firmó este acuerdo, Manuela vivía ya su idilio con el Libertador. Como Bolívar alistaba su campaña libertaria para el Perú, Manuela se preparó para acompañarlo y establecerse nuevamente en Lima. Por esta razón, dejó en Quito como su apoderado al comerciante don Pedro Sanz (no Sáenz), encargado de vigilar sus bienes y ejecutar el convenio suscrito con su tía Ignacia Aizpuru. Pedro Sanz fue recomendado por sor Josefa del Sacramento, quien crió a Manuela en el Monasterio de la Concepción (Orbes, 1973, p. 76).

Manuela regresó al Perú con el convencimiento de que su tía cumpliría a cabalidad el acuerdo. Sin embargo, doña Ignacia nunca entregó los 10,000 pesos a don Pedro Sanz, ni tampoco los intereses que comprometió pagar. Por este motivo, fue enjuiciada en rebeldía, y el Juez de Letras, Andrés Salvador, ordenó le sean confiscadas sus haciendas de San Isidro de Cotocollao y la de Chillo. Doña Ignacia adujo no tener efectivo para el cumplimiento de su compromiso, por lo que debió 
entregar otra hacienda suya, Santa Bárbara de Catahuango, vecina a la de Chillo, con cuya venta Manuela se cobraría los 10,000 pesos que se le adeudaban (AHN, Quito; Protocolos de escribano F. Matute, l/VIII/1826).

Doña Ignacia entregó la hacienda Catahuango a la autoridad correspondiente y ésta la sometió a remate el 29 de setiembre de 1826. El doctor José Barba Borja, capellán del Monasterio de la Concepción la adquirió por un monto de 9,908 pesos. Se conoció luego que esa adquisición fue hecha en realidad para el general Juan José Flores y Aramburu, al parecer por indicación expresa del Libertador (Villalba, 1986, p. 133).

Por fin, el 25 de octubre de 1826, don Pedro Sanz entró solemnemente en posesión de la casa hacienda de Catahuango, en nombre de doña Manuela Sáenz. La propiedad fue arrendada posteriormente a varias personas, entre ellas a don Ignacio Sanz, hermano del apoderado. Tanto el Libertador como Manuela invirtieron dinero para mejorarla y ponerla "en pie de producción", de este modo se le dotó de indios, herramientas y ganado. Por el lapso de una década, doña Manuela fue dueña de Catahuango, sin embargo, nunca recibió un centavo del administrador por los arriendos ni por las ganancias. Su ausencia prolongada del Ecuador a causa de su peregrinar en Lima, Nueva Granada, Jamaica y Paita, la obligó a vender en 1837 la propiedad "de cansada y aburrida". La venta se hizo a plazos a la señora Rosa Gangotena y Tinajero, y no fue nada provechosa para Manuela, porque dio por 6,000 pesos lo que valía, con las mejoras, hasta $15,000^{9}$.

9 Cartas de Manuela Sáenz a Roberto Ascásubi Matheu, fechadas en Paita, 11/VI/1846; 16/XII/1847 [mal fechada por error de impresión en 1841] ; 5/ XI/1845; 22/X/1846; 15/XI/1846; I6/VII/1 850; 8/VIII/1850. (Borja, 1946, pp. $237-250)$. 
Aparte de la hacienda Catahuango, Manuela tenía otras posesiones y negocios que dejó encargados a Pedro Sanz y otros conocidos (Murray, 2010, p. 226). Sin embargo, la mayoría de estas personas la engañó sistemáticamente o aprovechó de su lejanía en el norte peruano para no rendirle cuentas de lo que en justicia le correspondía. De allí que desde Paita se empeñara en conseguir intermediarios influyentes que le ayudaran a cobrarle a sus deudores. En principio, buscó el apoyo del presidente Juan José Flores a quien, desde el destierro paiteño, remitió varios poderes ${ }^{10}$. En carta del 7 de setiembre de 1843, Manuela le dice:

Mucho le agradeceré me haga pagar de las personas que me deben, como es la señora Gangotena y la señora Benítez, don Ignacio y don Pedro Sanz y de Jacobo Gómez, interesándose usted y sustituyendo el poder en el coronel Pareja, no dudo que saldré de mis ahogos que no son pocos ${ }^{11}$.

A pesar de las reiteradas cartas a Juan José Flores, los resultados no fueron muy halagüeños, salvo los pequeños préstamos que el mandatario le hiciera de forma personal. Manuela decidió pedir la colaboración de otro amigo suyo: Roberto Ascásubi Matheu, un abogado influyente y descendiente de una noble familia quiteña, a quien remitió poder amplio en noviembre de $1845^{12}$. $\mathrm{Al}$ parecer, las gestiones de este intermediario surtieron efectos positivos a diferencia de las de Flores, lo que vino a paliar en algo la situación económica de Manuela a partir de 1850 .

10 Un ejemplo de este aserto se encuentra en: Archivo Regional de Piura. "Poder especial para cobranzas dado por Manuela Sáenz al Sr. Juan José Flores, Presidente de la República del Ecuador". Legajo 139, f. 134v., Paita, 22/ IV/1840.

11 Carta de Manuela Sáenz a Juan José Flores, datada en Paita el 7/IX/1843. En Villalba, J..., 1986, p. 145.

12 Carta de Manuela Sáenz a Roberto Ascásubi, fechada en Paita, el 5/XII/1845. En Borja, L.F... p. 236. 
Con respecto a la herencia del padre de Manuela, don Simón Sáenz de Vergara y Yedra, éste no le dejó en su testamento ni bienes ni dinero en efectivo. Y por lo que se sabe, Manuela no siguió ningún trámite judicial de filiación paterna debido a que ambos habían convenido años antes de que la dote de los 8,000 pesos que él aportó al matrimonio con James Thorne sería el único legado al que ella podía aspirar.

Thorne, como es comprensible, invirtió los 8,000 pesos de la dote de Manuela en sus negocios particulares. Uno de esos negocios fue la sociedad que el inglés estableció con el general Domingo Orué y Mirones, un militar de la Independencia que ayudó de forma decidida con una serie de recursos (esclavos, dinero, animales, etc.) al Ejército de San Martín, cuando éste guerreó en el valle de Pativilca, Provincia de Chancay (hoy Barranca). En esta zona tenía el general Orué su productiva hacienda de caña llamada Huaito. Cuando el general San Martín ocupó Lima, Orué le acompañó en calidad de principal edecán. Más tarde, el Ejército realista ingresó a Huaito y la destruyó por completo. El general Orué fue diputado en el Congreso Constituyente de 1822. Pasada la guerra de la Independencia, el Estado lo recompensó parcialmente en merito a su colaboración con la causa patriota. Falleció Orué en Lima, en 1835, otorgando poder para testar a su gran amigo el inglés James Thorne (Leguía, 1972, t. III, n. 16, 21 , 24 y 25, pp. 174-177).

Con el tiempo, Thorne continuó administrando la hacienda Huaito, aunque tuvo conflicto por la propiedad con el coronel Justo Hercelles, quien reclamaba también tener algunos derechos sobre ella por ser parte de su herencia materna (Rumazo, 1979, p.234). Era la tarde del 17 de julio de 1847, cuando James Thorne paseaba con una de sus amancebadas 
por el interior de la hacienda, Buenaventura Concha ${ }^{13}$, segunda esposa y viuda del general Orué, cuando los dos fueron victimados por desconocidos. La noticia tuvo gran impacto que inclusive el diario $\mathrm{El}$ Comercio de Lima difundió información en los días sucesivos. Manuela tomó conocimiento del hecho luctuoso mediante un amigo entrañable que vivía en la capital, el abogado Cayetano Freyre, quien le escribe desde la capital una carta fechada el 23 de julio de 1847:

Mi buena Manuela:

Las enfermedades no me quieren soltar de sus garras (...). Por estas causales no he podido escribirte, pero no puedo prescindir de hacerlo en este día, aunque afectado en extremo por el desgraciado catástrofe que ha sucedido a tu marido en la Hacienda Huaito. Lo único que se ha sabido sobre su asesinato y de la mujer con quien estaba es lo que aparece en los Comercios del $21-20-19-18$ que te incluyo. Lo demás que se sepa con posterioridad te lo comunicaré oportunamente.

Yo creo que él dejó algunos bienes en dicha hacienda y también supongo que tienes algunas acciones que reclamar de su testamentaria en fuerza de los intereses que entraron en su poder de tu pertenencia. Sobre este particular no puedo hacerte ninguna indicación ni darte consejo porque no tengo datos positivos sobre ello, pero tú me puedes comunicar lo que más te plazca y halla de efectivo en este caso.

Opino y me parece preciso que te enlutes y para este fin me participarás, si quieres vestido de alepín-merino, u

13 Vid. "Sobre la averiguación de un asesinato realizado en la Hacienda Huito (Huacho, 21 de agosto de 1851). Causas Criminales, Manuscritos República, Justicia. 
algún olam francés para entre casa- Si usas medias negras y pañuelon de qué clase-, indicándome la persona con que quieres te mande esta encomienda.

Recibe muchos abrazos y también el corazón de este tu afectísimo que de corazón te ama.

Cayetano (Borja, 1946, p.246)

Aunque la relación conyugal de Manuela con James Thorne estaba rota desde hacía veinticinco años, habíanse reconciliado por medio de cartas en $1842^{14}$. Por tal motivo, ella quedó muy perturbada con la información de su repentina muerte, y lo expresa con estas palabras: “estoy enferma con la noticia del horrible asesinato de mi marido, pues aunque no vivía con él no puedo ser indiferente a este lamentable suceso"15. Sin embargo, las cosas no podían quedar así, y era necesario reclamar justicia. Con este fin, Manuela Sáenz acude ante el Juez de Paz del Puerto de Paita, don Juan Cañote, para que autorice a don Cayetano Freyre como su representante en Lima, mediante poder fechado el 29/XI/1 847 (registrado en Piura el 3/XII/1847 por escribano público Manuel Revoredo), para que interponga querella civil y criminal contra los individuos que perpetraron el homicidio de su finado esposo. Poder que luego conformó parte del "Expediente" que se abrió en los trámites conducentes para recuperación de lo que, en principio, creía le pertenecía: la dote que su padre don Simón Sáenz le entregó a James Thorne antes de sus esponsales.

14 Carta de Manuela a Juan José Flores, datada en Paita el 30 de enero de 1842. En esta epístola le dice la Libertadora a su amigo quiteño: "Sabrá usted que estoy de buenas con mi marido, me escribe con frecuencia, como amigo". En Villalba,...1986, p.115.

15 Carta de Manuela Sáenz a Roberto Ascásubi, fechada en Paita el 11 de agosto de 1847 [ la misiva tiene un error de impresión, pues aparece 1841]. En L. F. Borja, ... 1946, p.234. 
Manuel Escobar albacea, heredero y ex dependiente de James Thorne, hizo férrea oposición a la devolución de los 8,000 pesos, aduciendo que habían sido una dádiva graciosa y no propiamente una deuda a honrar en el futuro. Además, Manuela, al abandonar pública y escandalosamente a su marido (y unirse a Bolívar) había perdido legalmente el derecho de reclamar esa suma. En seguida respondió Cayetano Freyre que tal acusación no correspondía hacerla a Escobar, pues era parte del ámbito estrictamente privado de Thorne. Además, puntualizó que "si doña Manuela Sáenz se ha visto separada de su marido por algún tiempo, ha sido porque la conducta de éste la obligó a ello" (Academia Colombiana de Historia, 1954). Asimismo, Freyre recordó a Escobar que, en la cláusula 12 del testamento de Thorne, se reconocía la deuda en estos términos:

que le era deudor de esa suma a su mujer doña Manuela Sáenz de la cantidad de ocho mil pesos, que le fueron entregados en la ciudad de Panamá por su suegro el señor Simón Sáenz de Vergara y fue su voluntad que mientras se reunían fondos para el pago de la predicha cantidad, se pagase a la señora acreedora el interés del seis por ciento anual a fin de que ayude a sus gastos en el Pueblo en donde resida (AGN, Lima, Notario Juan Cosío, 1847, f. 249).

Cayetano Freyre para demostrar, ante el Juez de I ra. Instancia don Manuel Julio Rospigliosi, que Manuela, "residía en el estado más miserable de pobreza" presentó en Lima a una serie de escritos en los que recogió las declaraciones de los testigos a favor de su poderdante; entre ellos estaba: el Administrador de la Aduana del Puerto de Paita, don Gregorio Rafael Escalona: "le consta el estado de miseria de la señora Sáenz, (...) así como los socorros que recibe"; el Cónsul de Estados Unidos en Paita, Alejandro Rudens Jun: "le consta el estado de miseria en que se halla constituida la expresa doña Manuela Sáenz, tanto que el declarante por más de cinco años le he ministrado de alimento para su subsistencia. Que esto es público y 
notorio en aquel lugar, pues otras personas animadas también del mismo espíritu caritativo la auxilian con otras cosas necesarias para conservar su subsistencia"; el Diputado por Paita don Eugenio Raygada: "me consta que esta señora vive en la mayor indigencia y orfandad, subsistiendo de limosnas; por lo que creo de justicia que los Tribunales, sin el menor escrúpulo, deben declararla pobre de solemnidad"; el comerciante paiteño Manuel Mujica "conoce de trato y comunicación a doña Manuela Sáenz, (...) ese conocimiento le ha proporcionado ocasión de enterarse del estado miserable en que se halla la expresada señora Sáenz, tanto que su subsistencia la consigue principalmente por la filantropía de sus buenos amigos y otras personas caritativas"; el ex Gobernador de Piura, Cipriano Delgado: "toqué muy de cerca la escasez lamentable en que vive la referida señora, por falta de recursos de toda especie"; y el coronel (ecuatoriano) Carlos Vicendón: "visitó a doña Manuela Sáenz, por la amistad antigua que le tenía, y la ha visto reducida a la miseria". En el mismo sentido que los anteriores, declaró doña Josefa Puch de Valencia, quien luego de visitar a Manuela en Paita retornó a Lima en donde estaba avecindada (AGN, 1975, pp.256-270).

De lo expresado se deduce, pues, que, si bien hubo buena intención de parte de James Thorne de devolverle a Manuela Sáenz el total de la dote paterna, o por lo menos pagarle los intereses que generaba la no devolución del capital, su última voluntad nunca fue cumplida por la mala fe de su albacea Manuel Escobar, porque éste se las ingenió finalmente para amañar el juicio a su favor, con lo cual Manuela nunca cobró un centavo de lo dejado por Thorne, lo que vino a prolongar el sufrimiento de la pobre baldada hasta que muerte la liberó definitivamente de esa agonía.

¿Era realmente Palma un marino cuando conoció a la Sáenz?

De acuerdo a la vida marinera de Ricardo Palma que ha estudiado en profundidad Carlos Zúñiga Segura, al concluir el año de 
1855, el general José María Raygada, Comandante General del Departamento de Marina y Jefe de Armas del Callao, solicita al Ministro de Guerra y Marina general Luis La Puerta Mendoza que el joven Manuel Ricardo Palma Soriano sea destinado a servir en la oficina de la Mayoría de Ordenes de la Marina de Guerra del Perú, sin embargo, esta propuesta no fue aceptada de inmediato, por lo que vuelve a reiterarla a mediados de enero de 1856. El ministro La Puerta accedió finalmente a nombrar a Palma como Secretario de la Mayoría. Con su nombramiento bajo el brazo, el joven marino tiene la posibilidad de embarcarse como contador en uno de los principales buques con los que contaba entonces la Escuadra peruana: la goleta a vapor Loa (la cual tuvo vida útil entre los años 1855 y 1878; fue una nave de 575 toneladas; estuvo armada de cinco cañones: cuatro de 32 libras y uno de 8 libras; y su casco fue blindado desde 1866) (Ortiz, 2007, p. 302). Para abordar el Loa, Palma debió dirigirse al puerto de Arica en donde se hallaba atracada esa unidad naval desde algunos meses antes. Sobre esta etapa de la vida Palma, leemos a continuación:

De febrero a diciembre de 1856 [Palma] revista como Contador en el vapor Loa al mando del capitán de fragata Antonio A. de la Haza. El cargo de Contador en esa unidad era muy codiciado por los magníficos sueldos que se percibían, es decir setecientos veinte pesos anuales (60 pesos mensuales) más trescientos pesos de "gratificación de mesa" que no era otra cosa que el pago por encontrarse embarcado (Zúñiga, 2004, p. 41).

Ya en posesión de su nuevo cargo, Palma, como oficial 3ro. del Cuerpo Jurídico (o Político) de la Armada, tiene la oportunidad de realizar un periplo por los principales puertos del sur del Perú, así como de los del litoral de Bolivia (no se olvide que por aquellos años dicho país aún tenía salida al Océano Pacifico) y los de la costa de Chile, tales como Iquique, Arica, Caldera, 
Coquimbo, Valparaíso, entre otros. Al parecer dicho periplo duraría hasta fines de junio de aquel año. Poco más tarde, entre julio y setiembre, el Loa vendría a enrumbar proa hacia el norte peruano, en donde debió obligadamente tomar provisiones en la antigua ciudad-puerto de Paita por algunos días. Es en estas circunstancias en que se produjo el feliz encuentro entre: Ricardo Palma y Manuela Sáenz. Después de levar anclas, el Loa debió enrumbar hacia el mar del sur, ya que, según registros históricos, se puede asegurar que Palma, siendo parte de la tripulación de ese vapor participó, estando frente a la costa de Arequipa, de la insurrección de Vivanco contra Castilla, lo que aconteció el 16 de noviembre de 1856.

¿Cómo era el pueblo de Paita en la época de Manuela?

El médico cirujano René Primevère Lesson (1794-1849), quien fue también por su vocación naturalista destacado botánico y zoólogo, integró parte de una expedición de la Armada francesa que visitó diversos puertos de la costa del Pacifico sur. Las impresiones que acumuló en este periplo, las volcó luego en su obra: Voyage autour du monde entrepis par ordre du Gouvernement sur la corvette "La Coquille" (1826-1839). En este libro, Lesson describe ampliamente cómo era la ciudad-puerto de Paita en la primera mitad del siglo XIX, con lo cual se puede conocer de cerca la forma del paisaje o escenario que dio marco al encuentro entre Manuela Sáenz y Ricardo Palma. Al respecto, el viajero francés dice:

El pueblo de Paita está situado a cinco grados y algunos minutos de latitud meridional, al fondo de una bahía, o mejor dicho, de un golfo muy seguro, aunque enteramente abierto. Es de preguntarse quién ha podido ubicar en un punto desguarnecido de recursos un puerto sin importancia, cuyos alrededores son de una tremenda esterilidad. (...) 
El golfo de Paita está abierto desde nor-nor-oeste hasta el nor-nor-este, y los vientos que habitualmente soplan allí, son los de la parte sur. El mar es hermoso y tranquilo allí. Las casas están construidas sobre la cuesta de un barranco, $\mathrm{y}$ al pie de una llanura de una superficie uniforme, aunque elevada sobre un acantilado abrupto por encima de nivel del mar.

La población de Paita puede llegar a mil quinientos habitantes. Esta aldea ocupa un ángulo de la bahía, en el declive de la orilla, y está construida en anfiteatro. La mayor parte de las casas son cabañas construidas con cañas bravas, troncos de bambú, de quince a veinte pies de longitud, por un diámetro de cinco pulgadas, que participan de la propiedad de durar un siglo, sin deteriorarse. Los intersticios de estas cañas se llenan con barro o arena arcillosa; (...) Los techos, de cañahejas de las chacras, y que son traídas de lejos, se apoyan sobre trocos de bambú, tan sólidos como graciosos y ligeros. El aire penetra por todas partes en estas sencillas viviendas desprovistas de muebles, y en la que se cuelgan toscos utensilios caseros. Las casas de las personas notables están edificadas con fragmentos de piedra arenosa y de conchas, cubiertas de modo que tienen una galería en el primer piso. Así protegidos, los habitantes van a respirar frescura y a solazarse cada tarde de las fatigas del día. Como entre los del pueblo, ningún mueble confortable destinado a las comodidades de la vida, ningún adorno viene a destruir la desnudez chocante de estos asilos que se parecen a nuestros cuerpos de guardia: algunas esteras, extendidas sobre un piso de madera mal pulida y apenas elevada sobre el suelo, sirven de lecho en la noche, de sofá en el día, a todos los miembros de la familia. No obstante, la hamaca, este lecho movible y voluptuoso, tan apropiado para las costumbres afeminadas de los criollos, es el mueble de 
primera necesidad en cada casa. Su tejido es de rara finura, teniendo gran reputación los obreros de Guayaquil para estas confecciones. (...)

Las calles de Paita son derechas, y las cabañas, colocadas en dos o tres filas, están juntas y sólo con una separación entre ellas como para dejar entre los cuadros estrechos pasajes. Algunas tiendas dedicadas al servicio público bordean el mar, y ha sido instalado sobre la playa un cómodo desembarcadero; en la parte meridional, hay talleres para pequeños navíos, y durante mi permanencia había en construcción dos embarcaciones costeras. iPara esta escasa población se ha construido solamente dos iglesias!... Pese a que están techadas de paja, constituyen los más suntuosos monumentos de este lugar miserable, habiendo brillo en el interior con ese lujo con que los templos católicos, y especialmente los de España, tienen la vana y fútil manía de adornarse. Ante el altar mayor relucían hojas de plata repujada; (...) El fervor de las mujeres para las ceremonias de la iglesia, es muy pronunciado, y la costumbre de rezar sobre esteras extendidas sobre la piedra fría del atrio parece prometer una compunción más profunda. (...) La costumbre de colocar en las iglesias las sepulturas de la gente que puede pagar su sitio en estos santos lugares, es algo muy estimulado por el clero. Los despojos de los que no se puede sacar ningún dinero, son enterrados sin ceremonia, a algunos pasos de la aldea. (...)

Paita (...) es un lugar cómodo para la introducción de objetos de contrabando, el que se realiza allí casi abiertamente, no desdeñando siquiera autoridades tomar alguna parte en él. Hasta los mismos sacerdotes lo exaltan, porque en ello encuentran su interés; y por otra parte, los comerciantes, familiarizados con los prejuicios de los habitantes, no dejan procurar que aquéllos les sean ventajosos. (1971, pp. 363 y 373- 377). 
El testimonio del viajero alemán y hombre de negocios Heinrich Witt agrega algunas pinceladas más acerca de Paita que es interesante conocer:

Paita fue y todavía es (...) un lugar miserable. Su población consistía de indios y cholos con la reputación de ser buenos marineros. Las calles no están pavimentadas, se cortan unas a otras en ángulos rectos. Las casas están de caña cubierta de barro. Algunas están enlucidas y en su mayoría tienen un solo piso. Unas cuantas, (...) tienen uno o dos pisos más. La iglesia y la Plaza Mayor por supuesto no podían faltar en pueblo fundado por españoles. Recorrí un camino que llevaba a la alta explanada de arena que se extiende 14 leguas hasta Piura, pero al no ver un solo árbol o rastros de vegetación, rápidamente regresé sobre mis pasos. Paita no tiene agua y es traída en pequeños barriles a lomo de mula desde Colán, El Venal y La Huaca. Tres pueblos situados a una distancia de 5 ó 6 leguas sobre la rivera izquierda del río La Chira que llega al mar al norte de Paita (1992, p. 114).

Como puede concluirse, Paita era lugar paupérrimo en todos sus extremos; no obstante, allí decidió doña Manuela Sáenz vivir los 21 años de su postrera existencia. En la ciudad-puerto, la ex favorita del Libertador se ganaría la vida trabajosamente haciendo dulces, jarabes, ungüentos y, sobre todo, bordados que aprendió hacer de niña y adolescente en los conventos en donde estuvo expuesta. Algunas mercaderías de contrabando que mandaba a pedir al Ecuador fueron su medio de subsistencia. Así como las traducciones del inglés al español y viceversa que, de cuando en cuando, realizaba para las autoridades aduaneras, en la época en que en Paita recalaban muchos barcos balleneros y loberos de bandera inglesa y especialmente norteamericana, los cuales, luego de bajar anclas, se proveían de agua dulce, leña, artículos navales, aves de corral, carnes y pescados salpresos y toda clase de alimentos no perecederos que les permitiría a 
sus tripulaciones salir airosas de las faenas proyectadas en alta mar (Lofstrom, 2002, pp.20-42) . Sin olvidar, que, como todo puerto, Paita ofrecía también relajo y esparcimiento de todo tipo a los rudos marineros que por largos días y noches solo habían tenido contacto con los compañeros varones de la tripulación. Es así como en la ciudad-puerto surge necesariamente un barrio como el de Maintope (del inglés maintop ${ }^{16}$ ), en donde abundan casas de placer dedicadas a solazar los apetitos masculinos de la marinería y de todo aquel que pueda pagar los servicios de las hijas de Eva dedicadas al oficio más antiguo del mundo.

\section{La casa de Manuela en Paita}

Acerca de la casa (o cuatro lugares) donde vivió Manuela Sáenz en Paita (Poma, 2003, p.134), no se ha encontrado documento fehaciente que la acredite como titular de una propiedad, o arrendataria de un lugar temporal o permanente. Existe sí, una centenaria tradición oral que la ubica como habitante de, por lo menos, dos casas en la parte baja o antigua de la ciudad-puerto.

Cuando en 1923 el escritor y político peruano Luis Alberto Sánchez Sánchez recogía testimonios para su "libro periodístico" titulado: Sobre las huellas del Libertador, editado por la Librería Francesa y Casa Editorial Rosay (1925), tuvo la suerte de contactar con una de las ahijadas de doña Manuela Sáenz que aún sobrevivía. Se trataba de la octogenaria Paula Orejuela Castillo ${ }^{17}$, llamada por el apelativo familiar de "La

$16 \mathrm{Al}$ parecer esta denominación se debería a los marineros norteamericanos, que en la jerga propia de su oficio llaman así a la plataforma alta del palo mayor (cofa del mayor) (Lofstrom, 2002, p.43), en alusión al miembro viril erecto.

17 De acuerdo a la información que recoge Luis Enrique Tord Romero, en la Partida de Legitimación de los hermanos Orejuela-Castillo, doña Paula, hija de José María Orejuela y de Tadea Castillo, no sólo habría sido ahijada de Manuela Sáenz (nacida el 29/VI/1843), sino también su hermano Simón Francisco (nacido el 22/IX/1838). Víd. Tord. L.E. (1978). “Tras la sombra de Manuelita”. 
Morito". Según, afirmó esta testigo de excepción, su madrina "Manuelita" vivió en un pequeño segundo piso de una casa de alquiler hasta poco más del año 1847. Al parecer fue en esta casa en donde sufrió el accidente que la convirtió en una baldada. En el presente, dicho segundo piso con su pequeño balcón de madera incluido luce completamente destartalado y a punto de desaparecer ${ }^{18}$. Este lugar se localiza en la esquina de las calles del Zanjón y Ramón Castilla №101 (la misma que hoy conduce directamente a la moderna Basílica de Nuestra Señora de las Mercedes de Paita).

A raíz del accidente, doña Manuela debió solicitar a sus amistades el encargo de buscar un nuevo lugar para vivir, ya que su invalidez le imposibilitaba subir escaleras. Al parecer sus amistades encontraron finalmente para ella una casa de un solo piso, ubicada detrás de la anteriormente señalada, la cual queda hoy en la esquina de las calles del Zanjón y Nueva del Pozo N³90 (esta última llamada antiguamente calle de la Figurilla o del Mascarón). Esta fue la casa que sirvió de cobijo al encuentro de doña Manuela Sáenz y don Ricardo Palma, y que se menciona en las Tradiciones peruanas. Abona a esta tesis, la interesante y nutrida información que don Evaristo San Cristoval publicó en 1958, al editar el libro: Vida romántica de Simón Bolívar, Manuela Sáenz la Libertadora del Libertador. En esta obra se lee al respecto:

La casa que habitó la heroína en Payta (sic), aún se conserva, aunque algo variada su fisonomía particular. En 1922, el doctor Julio Villegas que en ese año desempeñaba el Consulado de Colombia en el Perú, recibió el encargo

En diario La Prensa de Lima, sábado 14/I/1978.

18 De acuerdo a lo poco que se ha podido saber acerca de los últimos propietarios de este inmueble, parece ser que la familia paiteña de apellido Argüelles fue la que vendió a la familia Gutiérrez Pacheco de Catacaos la casa de dos pisos. Vid. http://www.geocities.ws/consolidacionrepublica/cap02.html. 
del Plenipotenciario de aquel país, doctor Fabio Lozano Torrijos, de tomar una fotografía de la histórica casa, la que dicho sea de paso, está ubicada en la calle transversal con la plaza principal y a la espalda de la Iglesia de San Francisco, situada en la mencionada plaza, pero más próxima al Zanjón, lugar éste que arranca del borde de unas lomas y termina en el mar, pues fue abierto para que discurrieran por su cauce las aguas en tiempos de lluvias.

Con manifiesta diligencia, el doctor Villegas, distinguido y probo magistrado (...), inquirió por todo lo relacionado con la modesta residencia de Manuela Sáenz en Payta. Pudo así el doctor Villegas saber que la propiedad del citado inmueble fue de doña Tomasa Agurto de Vásquez, quien fue madre de las señoras Feliscar Vásquez de Artadi, Ventura Vásquez de Pérez y Tomasa Vásquez de Rentería, todas ellas ya fallecidas y que han dejado descendencia, dedicada a las actividades comerciales y agrícolas, tanto en la capital como en el departamento de Piura.

Fue en este albergue obligado, donde visitaron a Manuela Sáenz, ...entre otros, ... don Ricardo Palma, nuestro insigne tradicionista (p.46).

Es importante resaltar que la información publicada por San Cristoval, vino acompañada de una evidencia fotográfica anexa, gracias al lente del notable fotógrafo piurano Pedro Nolasco Montero Carrasco (1862-1941) ${ }^{19}$, quien fue contratado por el doctor Julio Villegas, como se ha mencionado ya "Cónsul de Colombia en el Perú”, y por el señor Francisco P. López, este último "caballero de elevada figuración social y comercial de esa localidad”, para plasmar en imagen la casa donde la tradición

19 Para mayores detalles de este importante fotógrafo piurano véase el extenso artículo de Andrés Garay Albújar "El rescate de una Piura perdida". En Semana suplemento del diario El Tiempo de Piura, domingo 26 de abril de 2009, pp. 1 1-14. 
oral de los antiguos vecinos del puerto aseguraba habitó en sus últimos años la favorita de Bolívar. De acuerdo a la brevísima descripción que entonces se hizo del inmueble, éste mostraba las siguientes características básicas:

Se trata de una construcción rústica hecha de cañas y adobe, con un techo pajizo como los que se estilaban en esos lugares cercanos al trópico. El año 1922 ofrecía el aspecto de no estar muy ruinosa, a pesar de las embestidas del tiempo, pero seguramente, y de habérsele cuidado en forma debida, se encuentra a la fecha [1958] bastante deteriorada y maltrecha (pp. 46-47).

Al pasar los años la casa fue legada a doña Feliscar Vásquez Agurto, quien casó en plena Guerra del Pacífico con el marino español Gabino Artadi Vidaguren (8-IV-1881). Más tarde, la propiedad fue parte de la herencia que recibió una descendiente de ambos, doña Estela Artadi de Seoane. Sin embargo, esta dama caritativa donó el inmueble a la Parroquia de Paita, que luego la puso en alquiler para procurarse unos ingresos ${ }^{20}$.

Como es comprensible, con los años la mencionada casa ha ido sufriendo algunos cambios tanto en su exterior como en su interior. Por ejemplo, su techo de paja original (llamado también de "torta de barro") cambió en la década de 1960 por un techo de calaminas de zinc, según aseveró el Regidor y Presidente de la Comisión de Educación y Cultura, profesor Víctor Villegas Arrunátegui, ocupante de la casa en 1994 (Moya, 1995, p. 179).

En la actualidad, la denominada casa de Manuela Sáenz en Paita, viene siendo habitada por varias décadas por la familia GodosCuray $^{21}$, aunque al parecer la posesión legal de la propiedad

20 Víd. http://www.geocities.ws/consolidacionrepublica/cap02.html

21 Gracias a la amable hospitalidad de la Sra. Mary Alexsandra Godos Curay se 
no está del todo esclarecida, lo que ha impedido llevar a cabo un proceso de expropiación por parte de las autoridades de la Región Piura o de la Municipalidad Provincial de Paita. Y los proyectos que se han propuesto o sugerido para restaurar la casa por iniciativa de instituciones locales, nacionales e internacionales (inclusive con ofrecimientos de ayuda económica de parte de los gobiernos de Ecuador, Colombia o Venezuela), han fracasado hasta el presente ${ }^{22}$, no habiéndose

\begin{abstract}
ha podido conocer el interior de esta casa, la que hemos visitado innúmeras veces desde el año 1995, ya sea de forma individual o acompañando a diversas personas o delegaciones extranjeras que han venido con el propósito específico de conocer la última morada de doña Manuela Sáenz en Paita, tal como han dejado evidencia de ello: el escritor danés Joachim Ramskov Boysen en 1999; la historiadora norteamericana y profesora de la Universidad de Alabama en Birmingham, Pamela Murray (2008, p. xii; 2010, p. 16); el periodista venezolano Ylich Carvajal Centeno divulgó su visita en amplio reportaje televisivo en el 2012, entre otros.
\end{abstract}

22 Por ejemplo, se puede mencionar que, en el 2011 , el Presidente del Gobierno Regional de Piura Javier Atkins Lerggios anunció en la clausura del V Foro de Integración Perú-Ecuador que se restauraría la casa de doña Manuela Sáenz, gracias al apoyo ofrecido por el Gobierno Autónomo Descentralizado de Loja, el cual se había comprometido a pagar el estudio del suelos, diseño arquitectónico y el expediente técnico de restauración del inmueble, mientras que el Gobierno Regional de Piura ejecutaría el proyecto en su totalidad. (Víd. "Restaurarán la Casa de Manuelita Sáenz. Compromiso Perú-Ecuador", en diario El Tiempo, Piura, miércoles 16 de noviembre de 2011 ); sin embargo, estos buenos propósitos no se han concretado hasta el presente. En otra oportunidad se ha hablado también no de restaurar la casa en sí, sino más bien de construir un modernísimo Centro Cultural dedicado a la memoria de Manuela Sáenz, en la parte alta de Paita, para lo cual el Gobierno Autónomo Descentralizado de la Provincia de Pichincha dirigido por el Prefecto Econ. Gustavo Baroja Narváez y su Viceprefecta Dra. Marcela Costales Peñaherrera firmaron con el Alcalde de la Municipalidad Provincial de Paita, Abog. Porfirio Meca Andrade un convenio para la realización del "Proyecto Binacional Perú-Ecuador Manuela Sáenz", con el fin de reivindicarla "como heroína y prócer en la gesta de la independencia y como precursora del feminismo en América Latina”. (Víd. Mazaheri, A. y Mosquera, M. (2014). Centro Cultural Manuela Sáenz. Quito: Dirección de Gestión de Infraestructura para el Desarrollo del Gobierno de Pichincha, p.5). Otras iniciativas vinculadas a revalorar la memoria de Manuela Sáenz en los últimos años sí han tenido rápida concreción e impacto, tales como el inicio de la Marcha Triunfal o cortejo de urnas de madera conteniendo 
podido concretar este anhelado sueño de constituir en el lugar una casa-museo dedicada a la memoria de tan insigne patriota de la Independencia hispanoamericana.

En el presente, cuatro son las placas de homenaje que ostenta la fachada de la vetusta casa. El orden cronológico de colocación es el siguiente:

\section{I) La primera de ellas es una sencilla placa de mármol de Carrara, que gestionó en su momento doña Eugenia Zúñiga de García ante el Consejo Directivo del Rotary Club asentado en el puerto}

los restos simbólicos de La Libertadora (en realidad tierra del subsuelo de la casa de Manuela Sáenz en Paita) con destino a Bolivia, Ecuador, Colombia y Venezuela, que se produjo el 3 de mayo de 2010. En Venezuela, la urna fue finalmente depositada, el 5 de julio de 2010, junto a la tumba de Simón Bolívar en el Panteón Nacional de Caracas, en donde previamente se le rindió los honores correspondientes al rango militar de Generala del Ejército de la República Bolivariana de Venezuela, designación póstuma otorgada por el Presidente Hugo Chávez Frías. Al igual que la designación que en el 2007 le otorgara el Presidente de la República del Ecuador, Rafael Correa Delgado. (Víd. "Campaña Triunfal de la mujer de Simón Bolívar. Manuela La Libertadora inicio su recorrido por América”, en diario El Tiempo de Piura, martes 4 de mayo de 2010; "Restos de Manuela Sáenz reposan junto al Libertador en el Panteón Nacional” en versión digital de Radio Nacional de Venezuela, AlbaCiudad 96.3 FM, o consultar en: https://albaciudad.org/2010/07/restos-de-manuela-saenzreposan-junto-al-libertador-en-el-panteon-nacional/; "Los restos simbólicos de Manuela serán depositados con los de Bolívar”, en versión digital de El Mundo en Orbyt, Bicentenario:

https://www.elmundo.es/america/2010/06/30/noticias/1277917835.html). Igual éxito ha tenido la creación del Corredor Turístico "Ruta Manuela La Libertadora, Quito-Paita”, que fuera impulsado por la Viceprefecta del Gobierno Provincial de Pichincha y Presidenta del Directorio de la Empresa Pública de Turismo Ciudad Mitad del Mundo historiadora Marcela Costales, quien en la presentación de la mencionada ruta dice: "Al presentar el Proyecto de la "Ruta de la Generala", no solamente describimos y tocamos puntos geográficos o lugares turísticos, sobre todo, recogemos la gloriosa alma andina, la unidad de nuestros pueblos en una historia común y la grandeza de nuestras jornadas libertarias, de las cuales Manuela Sáenz es uno de los íconos más altos y sobre todo, símbolo del espíritu invencible de toda mujer". (Víd. Costales, R. y Pesántes, R. (2015). Corredor Turístico Ruta Manuela La Libertadora. QuitoPaita. Quito: Gobierno de Pichincha, p. 7). 
(Moya, 1995, p.179), que a la par de justiciero homenaje debía ser un recordatorio permanente a los transeúntes de que:

\author{
(Símbolo rotario entre laureles) \\ EN ESTA CASA VIVIÓ Y MURIÓ \\ MANUELITA SÁENZ \\ LA LIBERTADORA DEL LIBERTADOR. \\ HOMENAJE DEL ROTARY CLUB DE PAITA.
}

PAITA, 28 DE JULIO DE 1970

II) La segunda placa fue colocada por la Municipalidad de Huaquillas perteneciente a la provincia ecuatoriana de El Oro, su enunciado reza:

LA ILUSTRE MUNICIPALIDAD DE HUAQUILLAS

REPUBLICA DEL ECUADOR

AL NOBLE PUEBLO DE PAITA, EXPRESA

SU GRATITUD POR HABER ACOGIDO EN

SU SENO A NUESTRA COMPTARIOTA Y LATINOAMERICANA

MANUELA SÁENZ

LUCHADORA POR LAS NOBLES CAUSAS

INDEPENDENTISTAS DEL LIBERTADOR SIMON BOLIVAR

HUAQUILLAS, JULIO DEL 2000

\author{
LIC. GONZALO CÁRDENAS \\ ALCALDE \\ ABOG. HERIBERTO MALDONADO \\ SECRETARIO
}


III) La tercera está colocada sobre un pedestal cuadrangular ubicado bajo el pórtico de la entrada a la casa, pedestal en el que descansa un busto de tosca factura con la imagen de doña Manuela Sáenz. En su texto se lee:

(Escudo de la Municipalidad)

MUNICIPALIDAD PROVINCIAL DE PAITA AQUÍ VIVIÓ LA LIBERTADORA DEL LIBERTADOR

LA ILUSTRE DAMA

MANUELA SÁENZ AIZPURU

EN HONOR A SU MEMORIA

Q.F. ALEJANDRO TORRES VEGA

ALCALDE PROVINCIAL DE PAITA

PAITA, 22 DE OCTUBRE DE 2009

IV) La cuarta placa de mármol blanco está fijada bajo la primera, y contiene una biografía resumida con los principales acontecimientos que marcaron la trayectoria vital de la ilustre quiteña en pro de la Independencia de América. Fue colocada con motivo de la promoción del "Corredor Turístico: Ruta Manuela La Libertadora”, que alentó desde la capital del Ecuador el Gobierno de Pichincha en alianza con la Municipalidad Provincial de Paita, el año 2014.

\section{Manuela Sáenz en las Tradiciones peruanas}

El especial carácter y temperamento exhibidos por doña Manuela Sáenz en su trayectoria vital, así como la celebridad que alcanzó por su valor y temple como patriota en la etapa de la Independencia, si bien es cierto la convirtieron en un personaje interesante para Ricardo Palma desde aquel encuentro paiteño, la verdad es que no es un personaje auroral de las primeras 
series de Tradiciones (recuérdese que la edición príncipe de la Primera Serie, impresa en los talleres de la Imprenta del Estado, salió recién a la luz en 1872).

Diecisiete años después de esa Primera Serie y luego de haber alcanzado parte del prestigio literario que anhelaba, el tradicionista se animó a incluir a doña Manuela Sáenz como personaje principal de un relato palmino, el mismo que ambientó en las postrimerías del virreinato e inicios de la República. Ello ocurrió cuando se publicó por primera vez: "La Protectora y la Libertadora. Monografías históricas", en la edición limeña de Perú. Ropa vieja. Última serie de tradiciones (que vendría a constituir en verdad la Séptima Serie), gracias al esforzado trabajo del impresor Carlos Prince, que la llevó a cabo en 1889. Esta tradición presentada en una sola unidad textual, comprendía tres relatos sucesivos numerados en romanos mayúsculos: I. "Doña Rosa Campusano", II. "Doña Manuela Sáenz", y III. "La Protectora y la Libertadora"23.

Más tarde, en 1924, la editorial española Calpe, volvería a traer esta tradición como parte de la Séptima Serie que reunió en Tomo IV de los seis que publicó entre 1923 y 1925. En esta oportunidad el título principal difirió, pues solo aparece "La Protectora y la Libertadora", y como subtítulo y entre paréntesis (Monografías Históricas), aunque conservó la sucesión de los relatos. La edición madrileña de Tradiciones peruanas completas de Aguilar de 1957 -que nos ha servido

23 La tradición unitaria a la que se hace referencia, apareció también en la revista literaria "El Perú Ilustrado" de Lima, sábado 1 de junio de 1889, año III, sem. I, n¹08, pp. 114-1 16, datada en abril de 1889. "El Perú Ilustrado” era editado por Peter Bacigalupi, tuvo como directores a José Santos Chocano, Abel de la E. Delgado, Clorinda Matto de Turner y Zenón Ramírez. (Miro Quesada, 1957, p. 175); Conservando la misma unidad, se le encuentra igualmente como parte de la Séptima Serie de Tradiciones publicada en 1896 y la Séptima Serie impresa en 1911. (Díaz, 2015, pp.164-165). 
de base para esta comunicación-, contempla por separado las narraciones, convirtiéndolas para el lector común en tradiciones independientes ${ }^{24}$

La cuarta narración de Tradiciones peruanas en la que se hace mención directa a doña Manuela Sáenz se llama "La carta de la Libertadora", que apareció publicada como parte de la Novena Serie de Tradiciones peruanas, editada en Lima por la Imprenta Torres Aguirre, en 1899, bajo el título de: Tradiciones y artículos históricos. Es importante mencionar que Palma reunió en este volumen los artículos históricos y literarios que la casa editorial española Montaner y Simón excluyó en su edición de $1893^{25}$.

\section{¿Cuál es el tratamiento que Palma da a doña Manuela Sáenz en sus tradiciones?}

El tradicionista para desarrollar el genio y figura de la quiteña Manuela Sáenz Aizpuru en sus Tradiciones peruanas utiliza un símil con otra compatriota suya, la guayaquileña Rosa Campusano Cornejo ${ }^{26}$. Y deja constancia de ello, cuando dice:

24 Estas tradiciones publicadas en la edición de Aguilar de 1957, pueden leerse de forma separada en las pp. 952-954, 962-963 y pp. $1132-1135$.

25 Según ha investigado acuciosamente Julio Díaz Falconí (2015, p.173) la tradición "La carta de la Libertadora" fue también impresa en otras publicaciones peruanas y extranjeras, como en el "Almanaque Sud Americano para 1899", que apareció en la capital de Argentina, a fines de 1898; en "El Comercio" de Lima, el lunes 26-XII-1898, n²2,054, pp.2-3 (en nota de pie de página dice: “Del elegante 'Almanaque Sud Americano para 1899' que acaba de publicarse en Buenos Aires tomamos el presente artículo"; Más tarde, en 1906, salió este relato como parte de Mis últimas tradiciones peruanas y Cachivachería; en revista "Prisma" de Lima, I3-VII-1907. Año III, n47; asimismo, formó parte de la $9^{\circ}$ serie de Tradiciones de 1925; y la recogió también la $2^{\circ}$ edición de Tradiciones peruanas completas, de Aguilar, Madrid, 1953.

26 Víd. Para una aproximación a este personaje histórico los artículos de: Arnaldo Mera Ávalos, "Rosa Campusano: patriota comprometida vista por la tradición de Palma y el historiador Germán Leguía y Martínez". En Aula Palma N XV, Lima, 2016 , Editorial Universitaria de la Universidad Ricardo Palma, pp. 195208; Jorge Luis Castro, "Una rosa para la libertad: doña Rosa Campusano 
"Yo, que tuve la buena suerte de conocer y tratar a la favorita de San Martín y a la favorita de Bolívar (...)” (1957, p. 962). Repárese como el tradicionista utiliza la palabra "favorita", dando a entender que la quiteña fue la principal entre varias queridas que pudo haber tenido el Libertador. Sin embargo, Manuela sabía bien, en lo más profundo de su fuero interno, que ella había sido más que eso en la vida del "Padre de la Libertad”. Fue fiel compañera, amiga, confidente...

Por otra parte, las referencias de Manuela Sáenz en las Tradiciones dejan vislumbrar cuál era el estereotipo de mujer en el periodo decimonónico. En esta etapa, al sexo femenino se cataloga, en líneas generales, como un género débil de carácter, frágil de sentimientos, ansiosa de protección masculina y convencida de que su sumisión al hombre es indispensable para la reproducción de la especie. Contribuía mucho en ello, la idea de educación relacionada a la mujer. Como bien explican María Mogollón y Ximena Narváez, en la época que le toco vivir a Manuela lamentablemente:

La educación femenina se enmarca dentro de parámetros que la excluyen de una perspectiva de superación al interior de la sociedad; se le asigna un papel secundario, sujeta al hombre a quien debe atender por "imposición de la Divina Providencia”. Se enfatiza en los "trabajos mujeriles", son asignaturas obligatorias: "higiene, economía doméstica, costura, bordado y tejido" y no sobrepasa el nivel escolar (1997, p. 72).

Cualquier intento de salirse de este esquema rígido era tener “aspiraciones varoniles"(Mogollón y Narváez, 1997, p. 77);

Cornejo en el Perú". En Revista del Archivo General de la Nación, N³1, Lima, 2016, Archivo General de la Nación, pp. 299-317; y la novela histórica de Silvia Puente, Rosita Campusano. La mujer de San Martín en Lima. Buenos Aires. Editorial Sudamericana, 2001. 
mientras que la figura opuesta, la del hombre, encarnaba siempre la fuerza física, la reciedumbre de carácter, la valentía, la inteligencia, la autosuficiencia, la capacidad de resolver conflictos, el liderazgo para encabezar todo tipo de iniciativas o movimientos efectivos (entre ellos los políticos), y, finalmente, el único que tenía "patente o licencia" para desbordar su gusto y caprichos en el terreno sexual. Por eso, es comprensible que en la primera mitad del siglo XIX si alguna mujer osaba asumir actitudes o "aspiraciones varoniles" era candidata segura para ser considerada socialmente como una persona "rara", "extraña" e incluso "antinatural”. Estas duras calificaciones parecen ser que fueron comunes aplicarlas a doña Manuela Sáenz por su persistente actitud “transgresora” (O’Phelan, 2019, p.49). Y ella nunca hizo nada para librarse de tales epítetos, más bien parecía que gustaba incentivarlos cada vez que podía. Un ejemplo que ilustra este comportamiento, es el levantamiento del pueblo de Quito, en 1823, aprovechando la partida de Bolívar hacia Lima. Las causas que provocaron dicho levantamiento fueron las excesivas cargas tributarias impuestas por el gobierno y la arrogancia de los militares grancolombianos que molestó a la población, ante ello Manuela decide actuar. Palma escribe: "Estos días en que Manuela se queda en Quito, se entrega por completo a la política. Fue entonces cuando, lanza en ristre y a la cabeza de un escuadrón de caballería, sofoca un motín en la plaza y calles de Quito" (1957, p. 1133).

La visión de "mujer recia" que en parte le ha dado Ricardo Palma a Manuela Sáenz en sus tradiciones, no es diferente a la de otros autores contemporáneos y posteriores. Éstos, en general, hacen hincapié en el comportamiento poco femenino que ella demostró en su accionar (montar a caballo, manejar armas de fuego, beber alcohol, hablar fuerte, lancear...), destacando que en su época vulneró las normas o límites impuestos a su género, que prohibían la participación de las mujeres en el gobierno y 
en toda la esfera pública. Esto, además, produjo incomodidad en muchos hombres, militares y civiles, que la Sáenz conoció, quienes, al verla vestida, algunas veces, con uniforme castrense (de "húsar", de "coronela", etc.) le dieron el calificativo de "indecente" o "loca", pero que tuvieron siempre que soportarla por ser la favorita del Libertador. Sobre el particular Pamela Murray expresa:

Algunos autores, partidarios de la imagen de la "chica mala" han interpretado la "loca" conducta de la quiteña como producto de una confusa identidad sexual o de género, como puede verse en la obra del popular autor peruano Ricardo Palma. En un ensayo escrito [-más apropiado sería decir en una tradición escrita-] a principios del siglo $\mathrm{xx}$, Palma describe a la Libertadora como una mujer-masculina. El autor sostiene que a diferencia de su afamada amiga Rosita Campusano, miembro prominente de la sociedad limeña a quien describe como mujer-femenina, Manuela Sáenz prefería los campamentos militares y las barracas al refinamiento urbano y los lujos de Lima. Ella "no sabía llorar" y había "renunciado a su sexo”, concluye. (...) Palma también indica que ella era "una naturaleza equívoca cuyas aspiraciones y espíritu masculino estaban en un cuerpo de mujer (Murray, 2010, p. 26).

Si bien Palma habla de "equivocación de la naturaleza" para el caso de Manuela Sáenz, no llega a los extremos del escritor colombiano Alberto Miramón, que en su obra La vida ardiente de Manuelita Sáenz, publicada en 1944, hace referencia a la supuesta desviación de género de Manuela, debido a una libido hiperactiva y mal encausada, que degeneró en una especie de tipología erótica de mujer que la ciencia moderna ha clasificado dentro de los parámetros del lesbianismo. Sobre el particular, debe indicarse que don Ricardo Palma al darle forma al personaje de Manuela Sáenz no llega al exceso de clasificarla 
dentro de esa tipología, como si lo hace, por ejemplo, en otras tradiciones y con otros personajes que nacieron mujer, tal es el caso de: "Juana la marimacho" refiriéndose a Juanita Breña, mulata capeadora de a caballo famosa en la Plaza de Acho y de varoniles inclinaciones (1957, pp.922-923); o en "iA Iglesia me llamo!" al relatar la vida escabrosa y bohemia de Catalina de Erauzo, la monja-alférez (1957, p. 192); o en "Mujer-Hombre" al contar la ingeniosas aventuras de María Leocadia Álvarez, encubierta para el mundo con el varonil nombre y facha de Antonio Ita (1957, pp.835-836).

Se postula más bien que la excesiva energía y el carácter recio que habría mostrado Manuela Sáenz desde el inicio de su vida junto al "Padre de la Patria" y que la llevó a invadir los ámbitos masculinos de la guerra y de la política, más que el hecho de querer mutar de género o convertirse en "un verdadero hombre", en realidad, lo que buscaba era tener el soporte psicológico y de autoestima que le permitiera enfrentar de "igual a igual" al "sexo fuerte" con el que trataba permanentemente (soldados, oficiales, políticos, altos funcionarios, etc.), con el único propósito de coadyuvar intensamente en la construcción de la imagen histórica o gloria de quien consideraba era el hombre de su vida: El Libertador Simón Bolívar.

Es interesante destacar, que el tradicionista en otro símil que plantea entre la Sáenz y su compatriota Rosa Campusano, advierte el aspecto intelectual que caracteriza a cada uno de estos personajes. Al respecto, Palma escribe:

Hasta en sus gustos literarios había completa oposición, Rosa (...) lectora de Eloísa y Abelardo y de libritos pornográficos (...) El Galante Arriza y el dulcísimo Meléndez (...)

iQué contraste con (...) Doña Manuela! Esta leía a Tácito y a Plutarco, estudiaba la historia de la Península en el 
Padre Mariano y la de América en Solís y Garcilaso; era apasionada de Cervantes y para ella no había poeta más allá de Cienfuegos, Quintana y Olmedo. Se sabía de coro el Canto a Junín y parlamentos enteros de Pelayo (1957, p. 963).

Otra forma de llegar a conocer el intelecto de Manuela Sáenz, es a través de las ideas que fluyen en sus cartas. Si bien en la época decimonónica era común que las personas instruidas desarrollaran el género epistolar como una forma válida y práctica de comunicación interpersonal, la verdad es que el caso de La Libertadora es particularmente excepcional en lo cuantitativo y lo cualitativo. Hasta el presente se han encontrado aproximadamente 250 cartas dirigidas a diversas personas de diferentes lugares de América del Sur, siendo indudablemente las misivas dirigidas al Libertador Bolívar, a su marido el inglés James Thorne, a familiares suyos y a amistades del Ecuador ${ }^{27}$ y otras naciones las más conocidas; esto gracias a que, por muchos años, se han conservado guardadas en colecciones particulares o han sido salvadas de la incuria. Reunir todas esas cartas en un solo epistolario, sería como tener contenida en un valioso cofre su vida misma. Interesante es anotar, que buena porción de esas cartas ha sido datada en Paita, según se ha podido comprobar al leer los originales en los archivos quiteños. Al respecto, el padre Jorge Villalba F., S.J. quien se dio también el trabajo de transcribir muchas de estas misivas, dice:

27 La correspondencia dirigida a amistades ecuatorianas es diversa, destacan los nombres de los siguientes destinatarios: Juan José Flores, Roberto Ascásubi Matheu, José Joaquín Olmedo, Luis de Saá, [Joaquín] Montúfar, Carmen Salinas, las señoras Ascásubis, Baltasara Josefa Calderón Garaycoa (viuda de Rocafuerte), Pacifico Chiriboga, etc. indican, como bien señala Luis Felipe Borja Pérez, que doña Manuela, a pesar de estar desterrada en Paita, "no perdió las consideraciones de la alta sociedad ecuatoriana” (1946, p.231). 
Las cartas de Manuela Sáenz tienen muchos méritos. Son fuentes de historia: mujer tan versada, tan observadora, tan relacionada con los hombres importantes de los países bolivarianos, nos ha dejado en sus epístolas, lo que llamaríamos sus Memorias.

(..) Con sus misivas se podría hacer la Historia de la Gran Colombia y del Ecuador, vista, interpretada y narrada por una mujer.

Mas estas cartas valen por sí mismas porque son joyas del estilo epistolar. Al leerlas, Manuela cobra vida, es como si nos trasladáramos a una tertulia suya en Paita. La oímos conversar, percibimos las inflexiones de su voz que alternan de lo pausado y solemne, de lo triste o violento, a lo ingenioso o pintoresco, en que se deja llevar del más refinado humor quiteño, de la sal de su tierra que nunca perdió (1986, p. 14).

Al leer las cartas manuscritas de Manuela se descubre, sin embargo, su mala caligrafía y su mala ortografía producto quizá de su endeble formación básica completada con esfuerzo autodidacta, persistente descuido en la redacción de los mensajes o premura al escribirlas para su rápido envío. Sobre el particular, el doctor Jorge Villalba agrega:

La letra de Manuelita es difícil de leer: ella misma lo advertía diciendo: "Usted dará al diablo mi letra y peor mi ortografía" [carta de Manuela Sáenz a Juan José Flores, Paita, 30/I/1843]. Y tenía razón. Su grafía es sumamente simplificada y rota; otras veces inesperadamente ligada: abundan las abreviaturas y letras similares; desconcierta la caprichosa ortografía (1986, p. 17) 


\section{El fin del trayecto}

Manuela murió, luego de una prolongada agonía, el 23 de noviembre de 1856. La causa de su deceso fue una epidemia de difteria que asoló a la gente del puerto de Paita por esas fechas, según carta del general venezolano Antonio de la Guerra a su mujer la piurana Josefa Goróstide Seminario $(5 / \mathrm{XII} / 56)^{28}$. Irónicamente, el baúl que contenía su correspondencia personal y algunos documentos que "La Libertadora" había guardado con tanto cuidado, fueron quemados junto con sus pertenencias para evitar un contagio mayor. Por esta misma razón sus restos mortales no fueron enterrados en el Cementerio San Pedro, en donde, desde 1805, se enterraba a los lugareños, sino más bien en un punto desconocido del tablazo o parte alta de Paita ${ }^{29}$.

Desde Paita, Manuela quiso de alguna manera colaborar con el general O’Learly, quien de regreso a Bogotá como Cónsul General de Gran Bretaña, estaba escribiendo sus Memorias, con el ánimo de levantar el monumento escrito más grande de homenaje a Simón Bolívar, su antiguo jefe y amigo. Cuando esta Memorias se empezaron a publicar en $1879^{30}$, cuarentainueve

28 Aurelio Miro Quesada Sosa fue bisnieto del general Antonio de la Guerra y guardaba en su archivo personal esta carta en mención. Vid. Miro Quesada, A. (1973). Piura en las tradiciones de Palma. (Colección Algarrobo №11). Piura: Universidad de Piura, p.35.

29 Al conocer el trágico fin de la amante de Simón Bolívar, el poeta chileno Pablo Neruda que indagó por los restos de Manuela cuando visitó Paita, en su trayecto de Valparaíso a Panamá, profundamente conmovido le dedicó una elegía que tituló: "La insepulta de Paita", que conforma parte de sus famosos "Cantos Ceremoniales [1959-1961]". Víd. Loyola, H. y Yurkievich, S. (eds.) (2005). Pablo Neruda. Obras Completas. t. II. Barcelona: RBA Coleccionables Instituto Cervantes, pp.991-1010.

30 Las Memorias del general O'Leary fueron publicadas en Caracas por la imprenta de la Gaceta Oficial de Venezuela, bajo el gobierno del presidente general Antonio Guzmán Blanco, de 1879 a 1883, y con la supervisión de Simón B. O’Leary Soublette, hijo del autor. La Obra constó de 32 volúmenes, los 26 primeros están numerados en romanos del I al XXVI; los tres siguientes 
años después de la muerte del Libertador, la figura de Manuela en lugar de ser relievada fue ocultada adrede por el gobierno de Venezuela, porque la imagen pública del Libertador de la América hispana no podía tener mácula alguna con ningún amor ilícito (Von Hagen, 1998, p. 260). Por muchos años las páginas dedicadas a la existencia de Manuela se "arrancaron" para la Historia oficial, pero el esplendor de la verdad se encargaría de reponerlas décadas después para hacerle justicia.

\section{A modo de conclusión}

En las Tradiciones peruanas en las que Palma nos habla sobre Manuela Sáenz descubrimos a una mujer fuera de lo común, en una época en que ser "transgresora" acarreaba toda una carga de censura social. Mas hay en ella aspectos positivos que el tradicionista ha destacado, como la firmeza y el temple de su carácter, la fidelidad a sus recuerdos íntimos, la sobriedad en el vivir, su preocupación intelectual a pesar de no haber tenido una educación formal. La energía desbordada que ella

conteniendo la narración escrita por el general Daniel Florencio O’Leary están numerados con los ordinales: primero, segundo y tercero, pero como este último, correspondiente al Apéndice fue eliminado, quiso disimularse esta falta numerando los tres siguientes, que contienen las cartas del Libertador con romanos XXIX, XXX y XXXI, en vez de ser el XXX, XXXI y XXXII. Con el pasar del tiempo, dicho tomo tercero-Apéndice fue recuperado por el nieto del general O'Leary, Julio D. Portocarrero O’Leary, quien hizo en 1914 la primera edición en Bogotá, gracias a la "Librería Americana". En este volumen aparece la "Conjuración del 25 de septiembre de 1828. Relación de una testigo ocular", en donde Manuela Sáenz describe pormenorizadamente el atentado contra Bolívar esa noche septembrina o nefanda, narración tomada en base a la carta que ella envió al general O'Leary desde Paita, el 10 de agosto de 1850. Al igual que el Apéndice, otras obras en las que hay referencia directa a Manuela Sáenz fueron silenciadas por muchos años, tal es el caso del llamado Diario de Bucaramanga de Luis Perú de Lacroix, que por su "ardiente contenido" privó a los lectores de las últimas confesiones del Libertador. Víd. Núñez, J. (1999). Un Hombre llamado Simón Bolivar. Guayaquil: Archivo Histórico del Guayas y Banco Central del Ecuador, pp.149 y ss. 
tradujo en su juventud en "aspiraciones varoniles" estaban esencialmente orientadas, más que a la búsqueda de placer con personas de su mismo sexo, al trabajo político de construcción de un pedestal de grandeza en la historia hispanoamericana para su amado El Libertador Bolívar. En ella las muestras de valor, coraje y estoicismo son una constante, pero también asoman en diversos momentos de su azarosa vida los gestos de nobleza, generosidad, abnegación, fidelidad y delicadeza, que le devuelven permanentemente a la feminidad propia de toda mujer. Estudiar algunos aspectos de la personalidad y carácter de Manuela Sáenz, vinculándola con otra figura grande como la de Ricardo Palma, es también una forma de hacerle justicia y de ayudar a descorrer el velo del olvido con el que la Historia la ha tratado de cubrir para no desdorar la grandeza del Libertador.

\section{Bibliografía}

Academia Colombiana de Historia. (1954). "Refutación de Cayetano Freyre contra los argumentos de Manuel Escobar en recuperación de dote de Manuela Sáenz". En Boletín de Historia y Antigüedades Vol. XLI, $\mathrm{N}^{\circ} 479-480$, setiembre-octubre.

Adriazola. J. C. (1999). “Manuela Sáenz, personaje integrador de Perú y Ecuador”, ponencia en II Jornadas de Historia Perú-Ecuador, un espacio compartido, organizadas por Departamento de Humanidades. Piura: Universidad de Piura.

Álvarez Saá, C., Villacís Molina, R. et al. (1995). Manuela. Sus diarios perdidos y otros papeles. / Manuela. Biografía. Entrevista imaginaria. Quito: Imprenta Mariscal.

Archivo General de la Nación. (1975). "Expediente judicial, de información de pobreza, seguido en nombre de doña Manuela Sáenz, La Libertadora del Libertador". En Revista del Archivo General de la 
Nación, Selección documental del periodo Bolivariano, Lima, N³, pp. 256-270.

Borja, L.F. (1946). “Epistolario de Manuela Sáenz”, en Boletín de la Academia Nacional de Historia antes Sociedad Ecuatoriana de Estudios Americanos. Vol. XXVI, julio-diciembre. Quito: Litografía e Imprenta Romero.

Costales, R., y Pesantes, R. (2015). Corredor Turístico Ruta Manuela La Libertadora. Quito-Paita. Quito: Gobierno de Pichincha.

Díaz Falconí, J. (2015). Tradiciones Peruanas. Cronología de las Tradiciones Peruanas. (3ra. ed. aumentada y corregida). Lima: Editorial Universitaria de la Universidad Ricardo Palma.

Jurado Noboa, F. (1986). "La familia y ascendientes de Manuelita. Las raíces hispánicas, americanas y judías en Manuela Sáenz Aizpuru”. En Villalba, J. (Estudio y selección). Manuela Sáenz. Epistolario. Quito: Ediciones del Banco Central del Ecuador.

Landázuri, C. (Estudio y selección) (1988). Vicente Rocafuerte. Epistolario. 2 t. Quito: Ediciones del Banco Central del Ecuador.

Leguía, G. (1972). Historia de la Emancipación del Perú: el Protectorado. VII t. Lima: Comisión Nacional del Sesquicentenario de la Independencia del Perú

Lesson. R. (1971). "Voyage autour du monde entrepis par ordre du Gouvernement sur la corvette "La Coquille" (1822-1824)". París: P. Pourrat Fréres Editeurs, 1839. [trad. por Ernesto More]. En Núñez, E. Relaciones de Viajeros (pp. 339-401). (Colección Documental de la Independencia del Perú). t. XXVII, vol. $2^{\circ}$. Lima: Comisión Nacional del Sesquicentenario de la Independencia del Perú.

Liévano, I. (1991). "Manuelita Sáenz" pp.121-138. En Gaitán de París, B. (comp.) La mujer en la vida del Libertador. Bogotá: Ediciones la Opinión Transversal. 
Lofstrom, W. L. (2002). Paita y el impacto de la flota ballenera norteamericana en el norte peruano 1832-1865. Piura: Caja Municipal de Ahorro y Crédito de Piura S.A.C. y Asociación de Historia Marítima y Naval Iberoamericana.

Loyola, H. y Yurkievich, S. (eds.) (2005). Pablo Neruda. Obras Completas. 5 t. Barcelona: RBA Coleccionables - Instituto Cervantes.

Mata, G.H. (1959). Refutación a "Las cuatro estaciones de Manuela. Los amores de Manuela Sáenz y Simón Bolívar" biografía de Victor W. von Hagen. Cuenca: Imprenta D. Toral L.

Mazaheri, A., y Mosquera, M. (2014). Centro Cultural Manuela Sáenz. Quito: Dirección de Gestión de Infraestructura para el Desarrollo del Gobierno de Pichincha.

Mera, A. (2016). "Rosa Campusano: patriota comprometida vista por la tradición de Palma y el historiador Germán Leguía y Martínez”. En Aula Palma $\mathrm{N}^{\circ}$ XV, pp. 195-208. Lima: Editorial Universitaria de la Universidad Ricardo Palma.

Miró Quesada Laos, Carlos. (1957). Historia del Periodismo Peruano. Lima: Librería Internacional del Perú, S.A.

Miró Quesada, A. (1973). Piura en las tradiciones de Palma. (Colección Algarrobo $\left.N^{\circ} 11\right)$. Piura: Universidad de Piura.

Mogollón, M., y Narváez, X. (1997). Manuela Sáenz presencia y polémica en la historia. (Biblioteca de Historia Ecuatoriana). Quito: Corporación Editora Nacional.

Murray, P. S. (2008). For glory and Bolivar. The Remarkable life of Manuela Sáenz, 1797-1856. Austin: University of Texas Press. (2010). Por Bolívar y la gloria. La asombrosa vida de Manuela Sáenz. Bogotá: Grupo Editorial Norma. 
Neuhaus Rizo Patrón, C. (2007). Damas, poder y política en el Perú. Lima: edición particular.

Núñez, E. (comp.). (1971). Relaciones de Viajeros. Colección Documental de la Independencia del Perú, t. XXVII, vols. $1^{\circ}$ - $4^{\circ}$. Lima: Comisión Nacional del Sesquicentenario de la Independencia del Perú.

Núñez, J. (1999). Un Hombre llamado Simón Bolivar. Guayaquil: Archivo Histórico del Guayas y Banco Central del Ecuador.

O'Phelan, S. (2019). Simón Bolivar y la conclusión de la Independencia en el suelo de los Incas. Lima: Fondo Editorial del Congreso de la República.

Orbes Moreno, C. (1973). "La Libertadora del Libertador, hija expósita. Un documento hasta ahora ignorado". En revista Humboldt, №52, República Federal de Alemania, pp. 76-77.

Ortiz, J., y Castañeda, A. (2007). Diccionario biográfico marítimo peruano. Lima: Asociación de Historia Marítima y Naval Iberoamericana.

Palma, R. (1957). Tradiciones peruanas completas. (Edición y prólogo de Edith Palma, nieta del autor, 3ra. ed.). Madrid: Aguilar.

Pérez, G.R (1997). Sin temores ni llantos. Vida de Manuelita Sáenz. Quito: Ediciones del Banco Central del Ecuador.

Peña, C. (1944). La Libertadora, el último amor de Simón Bolívar. Quito: Editorial La Moderna, S.A.

Poma, V. (2003). La generala Manuela Sáenz A. Perfil: político, militar e ideológico, su sepultura en Paita. El Oro: Gobierno Provincial Autónomo de El Oro y Academia Nacional de Historia del Ecuador.

Puente, S. (2001). Rosita Campusano. La mujer de San Martín en Lima. (Narrativas Históricas). Buenos Aires: Editorial Sudamericana. 
Real Academia Española (1964). Diccionario de Autoridades (Edición Facsímil del original de 1726). (vols. 1-3). Madrid: Editorial Gredos, S.A.

- (2014). Diccionario de la lengua española. (vigesimotercera edición). (vols.1-12). Lima: Planeta.

Rumazo, A. (1979). Manuela Sáenz. La Libertadora del Libertador. Madrid: Editorial Mediterráneo.

Sánchez, L.A. (1925). Sobre las huellas del Libertador. Lima: Librería Francesa y Casa Editorial.

San Cristoval, E. (1958). Vida Romántica de Simón Bolívar. Manuela Sáenz la Libertadora del Libertador. Lima: Ministerio de Guerra. Servicio de Prensa, Propaganda y Publicaciones Militares.

Stevenson. W.B. (1971). Memorias sobre las campañas de San Martín y Cochrane en el Perú. En Núñez, E. Relaciones de Viajeros (pp. 73338). (Colección Documental de la Independencia del Perú). t. XXVII, vol. $3^{\circ}$. Lima: Comisión Nacional del Sesquicentenario de la Independencia del Perú.

Susto, J. A. (1953). "El extraño caso de Juan Ignacio de Aizpuru”. En revista El Libertador, núm. 109, diciembre. Quito.

Tord. L.E. (1978). "Tras la sombra de Manuelita”. En diario La Prensa de Lima, sábado 14/I/1978.

Villalba, J. (Estudio y selección) (1986). Manuela Sáenz. Epistolario. Quito: Ediciones del Banco Central del Ecuador.

Von Hagen, V. (1998). Las cuatro estaciones de Manuela. (Narrativas Históricas). Buenos Aires: Editorial Sudamericana.

Witt, H. (1992). Diario 1824-1890. Un testimonio personal sobre el Perú del siglo XIX. Vol II (1843-1847). Lima: Banco Mercantil. 
Zúñiga, C. (2004). Ricardo Palma en la Marina. Lima: Fondo Editorial de la Universidad Ricardo Palma.

Zúñiga, L. (2013). Manuela. Loja: Plan Binacional de Desarrollo de la Región Fronteriza Perú -Ecuador y Municipalidad de Paita.

\section{Manuscritos}

-Archivo Arzobispal de Lima. Libro de casamientos de españoles, mestizos y cuarterones de la Parroquia de San Sebastián, 1788-1825. Partida de matrimonio de Jayme Thorne con Manuela Sáenz, 27/VII/1817.

-Archivo Metropolitano de Historia, Quito. "Contribuciones a las tropas patriotas" [Préstamo de Manuela Sáenz a la causa de la libertad, Libro Mayor, f. 89 v., 20 /V/1822]

-Archivo Histórico Nacional, Quito. "Expediente promovido por parte de Manuela Sáenz sobre su filiación y calidad" [Fondo Hijos Expósitos, Caja 5, 16/VI/1821].

Antonio Ribadeneyra, 31/VII/1823.

Protocolos de Escribanía Juan

- Protocolos de Escribanía

Francisco Matute, 1/VIII/1826.

-Archivo General de la Nación, Lima. "Expediente judicial, de información de pobreza, seguido en nombre de doña Manuela Sáenz, para reclamo de alimentos, dote y gananciales que le debía su finado esposo Jaime Thorne..." [Colección de la Corte de Justicia de Lima, Expedientes Judiciales. Causas ordinarias, 1848].

- "Testamento de don Jayme

Thornet, 25/X/1847. Notario Juan Cosío. Sección Historia. Protocolos, leg. 160 , fs. $248-251$ 
-Archivo Regional de Piura. "Poder especial para cobranzas dado por Manuela Sáenz al Sr. Juan José Flores, Presidente de la República del Ecuador". Legajo 139, f. 134v., Paita, 22/IV/1840.

\section{Webgrafía}

"Restos de Manuela Sáenz reposan junto al Libertador en el Panteón Nacional" en versión digital de Radio Nacional de Venezuela, Alba Ciudad 96.3 FM, o textual en: https://albaciudad.org/2010/07/ restos-de-manuela-saenz-reposan-junto-al-libertador-en-el-panteonnacional/. [Consultado el 18/IX/2019; 08:00 horas]

"Los restos simbólicos de Manuela serán depositados con los de Bolívar”, en versión digital de El Mundo en Orbyt, Bicentenario: https://www.elmundo.es/america/2010/06/30/noticias/1277917835. html). [Consultado el 5/VII/2019; 17.00 horas].

Recibido el 14 de noviembre de 2019 Aceptado el 21 de noviembre de 2019 